\title{
Current salt reduction policies across gradients of inequality- adjusted human development in the WHO European region: minding the gaps
}

\author{
Rodrigo Rodriguez-Fernandez ${ }^{1, *}$, Margarida Siopa ${ }^{2}$, Sarah J Simpson $^{3}$, \\ Rachel M Amiya ${ }^{4}$, Joao Breda ${ }^{5}$ and Francesco P Cappuccio ${ }^{6}$ \\ ${ }^{1}$ Institute of Tropical Medicine and International Health, Charité-Universitätsmedizin, Charitéplatz 1, 10117 \\ Berlin, Germany: ${ }^{2}$ Faculty of Food Science and Nutrition, University of Porto, Oporto, Portugal: ${ }^{3}$ School of \\ Public Health and Community Medicine, University of New South Wales, Sydney, Australia: ${ }^{4}$ Department of \\ Community and Global Health, Graduate School of Medicine, University of Tokyo, Tokyo, Japan: \\ ${ }^{5}$ Noncommunicable Diseases and Health Promotion, World Health Organization Regional Office for Europe, \\ Copenhagen, Denmark: ${ }^{6}$ Division of Mental Health \& Wellbeing, Warwick Medical School, WHO \\ Collaborating Centre for Nutrition, University of Warwick, Warwick, UK
}

Submitted 27 February 2013: Final revision received 28 May 2013: Accepted 4 June 2013: First published online 8 August 2013

\begin{abstract}
Objective: To assess current salt $\dagger$ reduction policies in countries of the WHO European Region against the backdrop of varying levels of human development adjusted for income, education and health (longevity) inequalities.

Design: Population-based, cross-sectional study, with data gathered through systematic review of relevant databases and supplementary information provided by WHO Nutrition Counterparts.

Setting: Member States of the WHO European Region.

Subjects: Inequality-adjusted Human Development Index scores were analysed against assessed levels of development and implementation of national nutrition policies and initiatives targeting population-level salt reduction.

Results: Within the WHO European Region, Inequality-adjusted Human Development Index values among countries with no existing salt reduction initiatives (mean 0.643 (SE 0.022)) were significantly lower than among those with either partially implemented/planned salt initiatives (mean 0.766 (sE 0.017 ),$P<0.001$ ) or fully implemented salt initiatives (mean $0 \cdot 780$ (se 0.021), $P<0 \cdot 001$ ).

Conclusions: Where salt reduction strategies are implemented as an integral part of national policy, outcomes have been promising. However, low- and middle-income countries may face severe resource constraints that keep them from emulating more comprehensive strategies pursued in high-income countries. Care must be taken to ensure that gaps are not inadvertently widened by monitoring differential policy impacts of salt policies, particularly regarding trade flows.
\end{abstract}

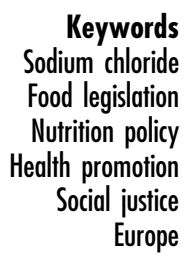

\section{The growing global burden of non-communicable diseases}

Non-communicable diseases (NCD) represent the leading causes of global mortality, accounting for more deaths than all other causes combined. They have been shown

$\dagger$ For the purposes of the current review, it should be noted that the word 'salt' is used throughout to refer to 'sodium' and 'sodium chloride' intake. In turn, the term 'salt intake' implies the reduction of total sodium intake from all dietary sources including, for example, additives (e.g. monosodium glutamate) and preservatives. to hit hardest in the world's low- and middle-income countries (LMIC) and populations, putting already weak and overburdened health systems under considerable $\operatorname{strain}^{(1)}$.

Accounting for the brunt of the NCD burden, CVD is the leading cause of deaths globally. While the CVD epidemic is receding in high-income countries, CVD mortality rates tend to be higher and are generally increasing in LMIC, where $80 \%$ of the estimated 17 million CVD-related deaths occur globally per year ${ }^{(2,3)}$. The most 
important risk factor for CVD is elevated blood pressure, which is estimated to cause 7.5 million deaths annually, the equivalent of about $12 \cdot 8 \%$ of all deaths worldwide ${ }^{(4)}$.

The causal link between salt intake and hypertension is well established, as is the role of salt as a major determinant of population blood pressure levels ${ }^{(5-7)}$. Furthermore, evidence supports the positive impact of reduced salt consumption in a corresponding reduction in blood pressure ${ }^{(8,9)}$. Given the elevated levels at which salt is consumed in the WHO European Region, centrally implemented national salt reduction strategies represent a highly cost-effective tool to reduce CVD risk and tackle the growing burden of $\mathrm{NCD}^{(10-13)}$.

\section{Global and regional salt reduction initiatives}

The WHO has recognized excess dietary salt intake as a global problem, and is working to facilitate salt reduction in countries worldwide. In 2003, WHO, in conjunction with the FAO of the UN, set a worldwide target of less than $5 \mathrm{~g}$ salt/d per person ${ }^{(14)}$, based on an extensive review of available evidence ${ }^{(5)}$. Since 2006, WHO has been supporting the development of national salt reduction strategies by establishing networks in partnership with regional organizations worldwide, including in the WHO European Region where a European Salt Action Network (ESAN) has been established involving twenty-seven countries facilitated by the WHO Regional Office for Europe.

Following a WHO technical meeting on 'Reducing Salt Intake in Populations' in Paris in 2006, recommendations were drafted to encourage the construction of national salt reduction programmes around three essential pillars: (i) product reformulation; (ii) consumer awareness and education campaigns; and (iii) environmental changes ${ }^{(15)}$ The corresponding actions to support achievement of these three recommendations can be summarized in eight essential steps (the first four of which are preliminary) ${ }^{(16)}$ :

1. organizing support to mobilize for change;

2. environmental scanning;

3. setting targets (national dietary guidelines on salt);

4. planning the campaign and engaging partners for implementation;

5. consumer awareness campaigns;

6. use of labelling to highlight the salt content of foods, and symbols/logos/text to identify low-salt products;

7. negotiating agreements with the food industry, catering industry, food retailers and restaurants to lower the salt content of a wide range of products; and

8. monitoring progress, continuous revision and evaluation.

In 2008, the European Union (EU) High Level Group on Diet, Physical Activity and Health developed a Framework for National Salt Initiatives, approved and adopted by EU Member States ${ }^{(17)}$. The overarching aim of the EU Framework is to support EU Member States towards achieving the WHO target salt intake of $5 \mathrm{~g} / \mathrm{d}$; as in the eight-step framework, the designated strands of activity are simultaneous and interconnected:

- data collection;

- establishing minimum benchmarks for major food categories;

- developing a nutrition labelling scheme that is consistent across EU countries;

- identification of a shortlist of twelve food categories that represent the largest potential opportunity for impact, from which countries must select at least five on which to focus;

- raising public awareness;

- industry engagement towards reformulation;

- a recognition of the need to reduce salt in foods at all price levels so that salt reduction benefits everyone; and

- monitoring and evaluation of actions and reformula$\operatorname{tion}^{(17)}$.

The framework also established a common minimum European benchmark for a $16 \%$ salt reduction from baseline 2008 levels over four years, to be realized across all food products in EU Member States.

\section{Social inequalities and salt}

The complexities of the shifting global dynamics in demographics, epidemiology and nutrition notwithstanding, one persistent trend spans the transitions: inequalities continue to grow through widening gaps in the distribution of key social determinants of health (e.g. secure employment and working conditions, income levels). Diet in particular has been implicated in the complex origins of the overall poorer health of those in lower socio-economic groups. In this way, income inequalities resulting in poor nutrition can create and exacerbate overall health inequalities.

The extent to which the quality of food intake is affected by socio-economic variables is confirmed by evidence coming not only from LMIC but from across the EU Member States as well ${ }^{(18)}$. Specifically, studies have established that members of higher socio-economic groups typically consume more within the modern recommended food groups (e.g. vegetables and fruit) but less within the traditionally recommended categories of food (e.g. bread and potatoes) ${ }^{(19,20)}$. More recently, the 2007 Low Income Diet and Nutrition Survey, conducted by the UK's Food Standards Agency, found that individuals on low incomes were generally less likely to consume wholemeal bread and vegetables, but were more likely to consume fat spreads and oils, non-diet soft drinks, pizza, processed meats and table sugar ${ }^{(21)}$.

Stemming from these patterns of dietary inequality, nutritional inequality has also been demonstrated in a number of studies. Regarding salt consumption, in the 2000-01 National Dietary and Nutrition Survey in Britain, salt intake was higher in low socio-economic groups after 
allowing for geographic gradients ${ }^{(22)}$. It has been proposed that higher salt intakes among the lower socio-economic groups amplify blood pressure levels and the risk of CVD. Poor fruit and vegetable consumption in this same population reduces potassium intake, another factor linked to high blood pressure ${ }^{(19,23-25)}$. Targeted preventive approaches to behavioural changes in low-income groups are unlikely to deliver sufficient improvements in number of portions consumed ${ }^{(26,27)}$. Similarly, foods rich in longchain n-3 PUFA (e.g. nuts or fish such as herring, tuna, sardines and wild salmon), which can limit sudden death from cardiac arrhythmia, may not be readily accessible to lower socio-economic groups ${ }^{(28)}$.

Inequalities in nutritional and economic status translate ultimately into inequalities in health. One study comparing data from the Health Survey for England 1996 with data from the Health Survey for England 2006 indicates a greater increase in obesity among low-income households compared with high-income households ${ }^{(29)}$. Unfortunately, there is evidence to suggest that the patterns in diet-related health inequality are only worsening ${ }^{(30)}$.

Significantly, Clark and colleagues ${ }^{(31)}$ have proposed that food consumption is not simply a matter of knowledge or rational choice for individuals of low socio-economic status, but rather is constrained by an ever-present sense of scarce resources and the need to prioritize other daily expenses perceived as being more important than a healthy diet. In this regard, food choice is not a separate or distinct element of life, but rather something embedded in lives characterized by stress arising from the need to continually reconcile scarce resources to meet a range of basic needs ${ }^{(31)}$. For example, a 2009 study that explored the views of ethnically and socio-economically diverse shoppers in New Zealand about the acceptability of economic incentives to promote healthier food purchases found that cost was the single most important influence on food purchases and participants were most interested in economic incentives for the fruit and vegetables group ${ }^{(32)}$. Global work on diabetes, equity and social determinants identified improving diet in disadvantaged populations as an important entry point, with action required at societal as well as individual level in order to change the broader food and/or obesogenic environment ${ }^{(33)}$.

Within the WHO European Region, the concept of food choice as a reflection of scarce resources is reflected in regional variations in the percentage of disposable income spent on food. Comparing the Eastern European region with the EU, up to $60 \%$ of disposable income is spent on food in the Eastern European states, compared with $22 \%$ in the $\mathrm{EU}^{(34)}$. The problem thus appears to lie largely in the environment in which food choices are made - in that the cheapest foods (e.g. ready-made and fast foods) tend also to be those with the poorest nutritional values and profiles. In this way, social inequalities are translated into nutritional and, ultimately, health inequalities, with levels of salt consumption factoring heavily into the equation. Hence, despite progress in improving health indicators in many countries, inequalities in health status - both between and within countries remain large ${ }^{(17,35)}$.

Ultimately, the link between CVD and poverty is bidirectional $^{(36,37)}$. In most countries, CVD hits hardest among the poor, who have greater risk factor exposure, tend to have more difficult access to health care and have less financial resilience to cope with the costs of disease management ${ }^{(38)}$. This has major collateral consequences at the household level ${ }^{(39)}$. In line with this pattern, it is now widely recognized that the rise of NCD is a major barrier to social and economic development ${ }^{(40)}$. This underlines the need to address social determinants and equity issues when designing programmes and health policy to reduce NCD not only in LMIC, but also in low-income groups within rich countries ${ }^{(36,40)}$.

At the country level, too, several studies have examined the general link between NCD and economic prosperity. A review undertaken in 2006, for example, found the cost of chronic diseases and their risk factors to be 'significant and sizeable', ranging from less than $1 \%$ to nearly $7 \%$ of national Gross Domestic Product ${ }^{(41)}$. Another study of twenty-three LMIC with high NCD burdens found that, without significant reductions in the NCD risk, an estimated \$US 84 billion of Gross Domestic Product would be lost between 2005 and 2015 due to just three NCD: CVD, diabetes and stroke ${ }^{(42)}$. Another study found that for every $10 \%$ increase in NCD-related mortality, annual economic growth would be reduced by $0.5 \%$, an estimate that prompted the World Economic Forum to rank NCD as one of the top global threats to economic development internationally ${ }^{(10)}$.

Against this backdrop, there is evidence that populationbased approaches and policies may inadvertently widen inequalities within a population (e.g. where the intervention is of greater benefit to more advantaged groups in the population - as measured by level of education, income, etc. - than to disadvantaged groups $)^{(43,44)}$. Many population-based health interventions are cost-effective and can have a rapid impact on the burden of disease at the population level; for example, raising taxes on tobacco, restricting access to retailed alcohol and reducing the salt intake and salt content of food. However, attention needs to be paid to the differential impact on different segments within the population including socially disadvantaged groups ${ }^{(45,46)}$, particularly where there are potentially high levels of inequality within the country. Data about differential impact are important to ensuring the effectiveness of population-based initiatives in terms of coverage and impact (i.e. reaching all groups in the population).

Hence, the present study was undertaken to identify and review national policies related to salt reduction among countries belonging to the WHO European 
Region. With a view to gauging the broader implications, the presence of such policies was assessed against the backdrop of varying levels of human development adjusted for inequalities in income, education and health (longevity). Our literature review thus sought to shed light on the potential linkage between national salt reduction initiatives and prevailing social inequalities among the European Member States. In doing so, we aimed to reflect on and contribute to ongoing debates surrounding salt reduction policy strategy development and implementation at national, regional and global levels.

\section{Methods}

\section{Data collection}

Evidence was mined from the data management website for the WHO European Database on Nutrition, Obesity and Physical Activity (NOPA), which compiles information for the WHO European Member States to monitor progress on nutrition, diet, physical activity and obesity. The available country information includes national and sub-national surveillance data, policy documents, action to implement policy and examples of good practice in programmes and interventions. Consultation on NOPA was used to identify relevant national policies related to salt reduction.

Additional information on existing salt reduction initiatives was compiled through electronic communication with the WHO Nutrition Counterparts in the European Member States. To this end, a written request for information was dispatched via email through the WHO Regional Office for Europe to the appropriate representative in each Member State. When a response was not received after 2 months, a direct telephone call was made to follow up. A total of forty-three countries replied to requests for up-to-date information regarding the existence and extent of current salt reduction activities being implemented at the national level, as well as those planned for future implementation.

Relevant electronic databases including biomedical and health science, social science, health policy, nutrition and WHO regional databases were searched until April 2012 using a pre-determined search strategy. Bibliographies of those papers containing pertinent information on national salt reduction policies in place among the European Member States at the time of review were then searched by hand to identify any further relevant references, which were subject to the same screening and selection process. Identified references were screened independently by two reviewers using a three-stage approach: selecting studies deductively first at the title (Stage 1), then at the abstract (Stage 2) and finally at the article content (Stage 3) level based on relevance to our objectives. All types of evaluative study designs were eligible for inclusion; studies were not selected based on methodological quality. Purely theoretical models and historical recapitulation, meanwhile, were excluded, as our goal with this review was to provide conclusions based on empirical data.

Governmental websites pertaining to the Ministry of Health, National Public Health Institutes, Ministry of Sanitation and Welfare or any other pertinent governmental agencies were hand searched in order to identify additional national policies or initiatives. Websites of nongovernmental organizations, scientific associations and any other credible source involved with salt reduction initiatives either nationally or internationally were also consulted.

Finally, technical reports from government agencies or scientific research groups, working papers from taskforce groups or committees, as well as white papers or preprints were also included. Reports from the European Commission, WHO and the Collaborative Action for Risk Factor Prevention and Effective Management of NCDs (CARMEN) were further consulted.

\section{Data analysis}

Information related to the five key elements of the EU framework as well as the eight essential steps proposed by WHO was extracted from the multiple data sources. Key characteristics from each country were placed in a matrix encompassing six elements: (i) current national initiative; (ii) baseline assessment; (iii) consumer awareness; (iv) labelling; (v) industry involvement; and (vi) monitoring and evaluation initiatives. Current national initiatives were classified as 'fully implemented', 'partially implemented/ planned' or 'non-existent' depending on the elements contained within the salt reduction plan, based on the previously mentioned salt reduction frameworks.

As a measure of actual levels of human development (taking prevailing inequalities into account) achieved within Member Nations, we used United Nations Development Programme data on the Inequality-adjusted Human Development Index (IHDI) scores for each country. While the UN Human Development Index (HDI) is a combined measure of the national average of health, education and income, the IHDI goes one step further. Beyond the average measure for each dimension within a country, this measure reflects how the achievements in health, education and income are distributed across the population. The higher the level of inequality, the greater will be the decrease in the value of each area (health, education and income) depending on the level of inequality.

In this way, the IHDI accounts for inequalities in human development that may exist across a population within the same country. Hence, the IHDI will be the same as the HDI in the case that there is no inequality in the population but is less than the HDI as inequality increases. Taking this into account, the IHDI is the actual level of human development as it accounts for inequality, while the HDI can be viewed as an index of 'potential' human development that could be reached if there was no inequality. The 'loss' in potential human development 
due to inequality is thus given by the difference between the HDI and the IHDI ${ }^{(47)}$.

Statistical analysis of such data was performed using the statistical software package SPSS version 18 for Macintosh. The grouped samples were examined for normality and homogeneity of variance, consistent with assumptions for univariate ANOVA. One-way ANOVA methods were then used to estimate the mean differences in IHDI scores in relation to the different levels of national salt initiative implementation (none, partially implemented/planned, or fully implemented) across countries in the WHO European Region. In addition, as exploratory analysis, the post hoc Tukey Honestly Significant Difference test was performed to make pairwise comparisons between groups. Results of statistical tests were regarded as statistically significant if the associated $P$ values were less than $0 \cdot 05$. In this way, we sought to broadly identify any potential patterns between the IHDI and the status of the country's salt reduction initiative.

\section{Results}

In the WHO European Region, twenty-six of the fiftythree Member States have operational salt education policies in place. In some Member States, however, activities are carried out by advocacy groups or research institutions even though formal salt reduction policies are absent at the national level.

When it comes to the existence of baseline assessment data, thirty Member States have carried out activities in this area - whether it is by urine analysis (namely $24 \mathrm{~h}$ urine collection), dietary intake survey or salt levels in food categories. In total, thirty-two Member States have initiated some form of consumer awareness activity, either through a governmental programme or through the involvement of a non-governmental advocacy organization, rarely by industry ${ }^{(11,48)}$ (Table 1 ).

Labelling activities have been carried out or are planned in sixteen Member States and vary in terms of being voluntary or regulated by legislation. Industry involvement was found to be voluntary in the majority of cases and spanned a variety of activities including food reformulation and producing toolkits for the general public as part of corporate responsibility initiatives.

Monitoring and evaluation activities were planned or carried out in twenty-four Member States in the form of urine analysis, sampled commercial food products and campaign awareness effect measurements. Voluntary selfreporting by industry was also described. However, no action or monitoring of food trade flows with regard to salt was reported by any of the Member States, nor was any such coordination identified in the literature review.

In comparing the country IHDI against the current status of the national salt reduction initiative, we found that countries classified as having no existing initiative
(Category 1) tend to be lower on the IHDI scale (i.e. they have lower mean levels of actual human development due to inequality and other factors) than those with partially implemented/planned or fully implemented initiatives (Fig. 1). However, as depicted in Fig. 1, two countries bucked this trend notably: Germany (with a high IHDI score and no national salt reduction initiative) and Turkey (with a low IHDI score and a fully implemented national salt reduction initiative).

One-way ANOVA showed a significant difference in IHDI based on the different levels of salt initiative implementation. Specifically, the post hoc Tukey Honestly Significant Difference test indicated that IHDI values among countries with no existing salt reduction initiatives (mean 0.643 (SE 0.022)) were significantly lower than for those with either partially implemented/planned salt initiatives (mean 0.766 (sE 0.017 ),$P<0.001$ ) or fully implemented salt initiatives (mean $0 \cdot 780$ (SE $0 \cdot 021$ ), $P<0 \cdot 001$ ). However, no significant difference in IHDI values was detected between countries with partially implemented/planned salt initiatives as compared with fully implemented salt initiatives $(P=0 \cdot 867)$.

Overall, countries with greater financial resources seemed to correspond with those presenting more mature salt reduction initiatives. At the same time, several champion examples (Bulgaria, Estonia, Hungary and Turkey, for example) have demonstrated that national initiatives are not the exclusive province of the generally more affluent Western European region, and salt reduction initiatives have also gained importance on the political agenda in countries labelled as low- or middle-income by World Bank classifications.

\section{Discussion}

\section{Breaking the cycle}

The findings of the present study underline a clear link between national salt initiatives and levels of inequalityadjusted human development across the WHO European Region. Given the socio-economic disparities surrounding salt intake ${ }^{(22)}$ and the established health benefits of dietary salt reduction ${ }^{(8,9)}$, this observed tendency towards limited policy responses on salt among less developed, resource-limited countries is troubling - and highlights a major missed opportunity. Without adequate attention, such gaps are liable to feed into widening health and social inequalities (Fig. 2). On the other hand, wider application of population-level salt reduction programmes presents a potentially cost-effective, if not cost-saving, path to reducing CVD burdens across population strata ${ }^{(12,13)}$, both nationally and at the global level.

Of course, the concept of expanding salt reduction recommendations from high-risk groups to the general population has not been without controversy. A vibrant debate is ongoing in health research and action communities 
Table 1 Current status of salt reduction initiatives within the WHO European Region Member States

\begin{tabular}{|c|c|c|c|c|c|c|c|}
\hline & $\begin{array}{l}\text { Current national } \\
\text { initiative }\end{array}$ & $\begin{array}{c}\text { Baseline } \\
\text { assessment }\end{array}$ & $\begin{array}{l}\text { Consumer } \\
\text { awareness }\end{array}$ & Labelling & $\begin{array}{l}\text { Industry } \\
\text { involvement }\end{array}$ & $\begin{array}{l}\text { Monitoring \& } \\
\text { evaluation }\end{array}$ & $\begin{array}{l}\text { Salt intake } \\
\quad(g / d)\end{array}$ \\
\hline Albania & - & - & - & - & - & - & - \\
\hline Andorra & $x$ & $\checkmark$ & $\checkmark$ & $x$ & $x$ & $x$ & $7 \cdot 5$ \\
\hline Armenia & - & - & - & - & - & - & - \\
\hline Austria & $\checkmark$ & $\checkmark$ & $\checkmark$ & $x$ & $\checkmark$ & $\checkmark$ & 8.5 \\
\hline Azerbaijan & - & - & - & - & - & - & - \\
\hline Belarus & - & - & - & - & - & - & - \\
\hline Belgium & $\checkmark$ & $\checkmark$ & $\checkmark$ & $x$ & $\checkmark$ & $\checkmark$ & 7 \\
\hline Bosnia \& Herzegovina & - & - & - & - & - & - & - \\
\hline Bulgaria & $\checkmark$ & $\checkmark$ & $\checkmark$ & $x$ & $\checkmark$ & $\checkmark$ & $13 \cdot 8$ \\
\hline Croatia & $\checkmark$ & $x$ & $x$ & $x$ & 0 & $\checkmark$ & - \\
\hline Cyprus & $\checkmark$ & $\checkmark$ & $\checkmark$ & $x$ & $\checkmark$ & $x$ & 5 \\
\hline Czech Republic & $x$ & $\checkmark$ & $\checkmark$ & O & $\checkmark$ & $x$ & $13 \cdot 6$ \\
\hline Denmark & $\checkmark$ & $\checkmark$ & $\checkmark$ & $\checkmark$ & 0 & $\checkmark$ & $8 \cdot 6$ \\
\hline Estonia & $\checkmark$ & $\checkmark$ & $\checkmark$ & $\checkmark$ & 0 & $\checkmark$ & 10 \\
\hline Finland & $\checkmark$ & $\checkmark$ & $\checkmark$ & $\checkmark$ & $\checkmark$ & $\checkmark$ & 8 \\
\hline France & $\checkmark$ & $\checkmark$ & $\checkmark$ & $\checkmark$ & $\checkmark$ & $\checkmark$ & 9 \\
\hline Georgia & $x$ & $x$ & 0 & $x$ & $x$ & $x$ & - \\
\hline Germany & $x$ & $\checkmark$ & $\checkmark$ & $x$ & $x$ & $\checkmark$ & $7 \cdot 8$ \\
\hline Greece & $\checkmark$ & $x$ & $\checkmark$ & $\checkmark$ & 0 & $x$ & - \\
\hline Hungary & $\checkmark$ & $\checkmark$ & $\checkmark$ & O & $\checkmark$ & $\checkmark$ & $14 \cdot 8$ \\
\hline Iceland & $x$ & $\checkmark$ & $\checkmark$ & - & 0 & $\checkmark$ & 8 \\
\hline Ireland & $\checkmark$ & $\checkmark$ & $\checkmark$ & $\checkmark$ & $\checkmark$ & $\checkmark$ & 8.9 \\
\hline Israel & - & - & - & - & - & - & - \\
\hline Italy & $\checkmark$ & $\checkmark$ & $\checkmark$ & 0 & $\checkmark$ & $\checkmark$ & 10 \\
\hline Kazakhstan & - & - & - & - & - & - & - \\
\hline Kyrgyzstan & - & - & - & - & - & - & - \\
\hline Latvia & $x$ & $\checkmark$ & $\checkmark$ & $x$ & 0 & $\checkmark$ & $7 \cdot 1$ \\
\hline Lithuania & $x$ & $\checkmark$ & $\checkmark$ & O & O & $\checkmark$ & 9 \\
\hline Luxembourg & $x$ & $x$ & $\checkmark$ & $\checkmark$ & 0 & $x$ & - \\
\hline Malta & $\checkmark$ & $x$ & $\checkmark$ & $x$ & O & $x$ & - \\
\hline Monaco & - & - & - & - & - & - & - \\
\hline Montenegro & $\checkmark$ & $x$ & $x$ & $x$ & 0 & $x$ & - \\
\hline Netherlands & $\checkmark$ & $\checkmark$ & $\checkmark$ & $\checkmark$ & O & $\checkmark$ & 9 \\
\hline Norway & $\checkmark$ & $\checkmark$ & $\checkmark$ & $\checkmark$ & $\checkmark$ & $\checkmark$ & $8 \cdot 6$ \\
\hline Poland & $\checkmark$ & $\checkmark$ & $\checkmark$ & $x$ & $\checkmark$ & $\checkmark$ & 7 \\
\hline Portugal & $x$ & $\checkmark$ & $\checkmark$ & $\checkmark$ & $\checkmark$ & $\checkmark$ & 12 \\
\hline Republic of Moldova & - & - & - & - & - & - & - \\
\hline Romania & $x$ & $\checkmark$ & $\checkmark$ & $x$ & $\checkmark$ & $x$ & 11 \\
\hline Russian Federation & - & - & - & - & - & - & - \\
\hline San Marino & - & - & - & - & - & - & - \\
\hline Serbia & $x$ & $\checkmark$ & $x$ & $x$ & $x$ & $x$ & - \\
\hline Slovakia & $\checkmark$ & $\checkmark$ & $\checkmark$ & $x$ & 0 & $x$ & 8 \\
\hline Slovenia & $\checkmark$ & $\checkmark$ & $\checkmark$ & $x$ & 0 & $\checkmark$ & 12 \\
\hline Spain & $\checkmark$ & $\checkmark$ & $\checkmark$ & $x$ & O & $x$ & 10 \\
\hline Sweden & $\checkmark$ & $\checkmark$ & $\checkmark$ & $x$ & $\checkmark$ & $\checkmark$ & 11 \\
\hline Switzerland & $\checkmark$ & $\checkmark$ & $\checkmark$ & $x$ & $\bigcirc$ & $\checkmark$ & 9 \\
\hline Tajikistan & - & - & - & - & - & - & - \\
\hline $\begin{array}{l}\text { The Former Yugoslav Republic of } \\
\text { Macedonia }\end{array}$ & - & - & - & - & - & - & - \\
\hline Turkey & $\checkmark$ & $\checkmark$ & $\checkmark$ & 0 & 0 & $\checkmark$ & 18 \\
\hline Turkmenistan & - & - & - & - & - & - & - \\
\hline Ukraine & - & - & - & - & - & - & - \\
\hline United Kingdom & $\checkmark$ & $\checkmark$ & $\checkmark$ & $\checkmark$ & $\checkmark$ & $\checkmark$ & $8 \cdot 7$ \\
\hline Uzbekistan & 0 & $x$ & $x$ & $x$ & $x$ & $x$ & - \\
\hline
\end{tabular}

$\checkmark$, fully implemented; $\odot$, partially implemented/planned; $\mathbf{x}$, no action; - , data unavailable.

concerning the potential effectiveness of public policy in regulating salt intake. In particular, uncertainties stemming from the difficulties in evaluating populationtargeted interventions in randomized controlled trials remain ${ }^{(49)}$. Some authors have suggested, for example, that efforts to effect sodium reduction in the general food supply could be offset by consumers' discretionary salt use $\mathrm{e}^{(50,51)}$, although no direct evidence to support such compensation for reduced-sodium foods exists ${ }^{(44,52)}$. On the other side, numerous expert advisory panels - including those convened both independently and by government agencies - have consistently and repeatedly concluded, after careful evaluation of the available data and stakeholder concerns, that the evidence and public health concerns warrant worldwide implementation of a strategy of gradual salt intake reduction at the population level ${ }^{(8,10,11,50,53)}$. 


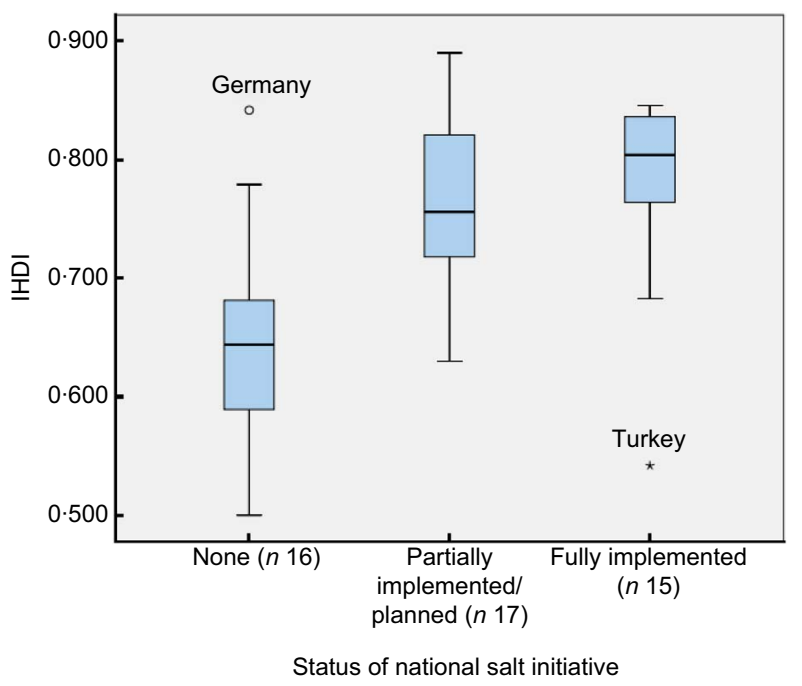

Fig. 1 (colour online) Box-and-whisker plot showing Inequalityadjusted Human Development Index (IHDI) by current status of the national salt initiative within Member States of the WHO European Region ( $n$ 48; five countries (Andorra, Malta, Monaco, San Marino and Turkmenistan) excluded due to missing IHDI data). Middle line in the box represents the median; the bottom and lower edges of the box represent the interquartile range (IQR; 25th to 75th percentile); the whiskers represent the range; $O$ is an outlier; and $\star$ is an extreme value

\section{Challenges and barriers to change}

When developing salt reduction policies, it is important to acknowledge that each country faces a host of challenges and barriers that come with implementing, executing and assessing any national intervention, as our review and analyses have highlighted. Countries may have limited capacity and resources to implement new programmes. Baseline data needed to guide policy, for instance, are not always readily available. The $24 \mathrm{~h}$ urine test method regarded as the gold standard for assessing salt intake is simply beyond the resource capacity of many countries. On the other hand, experience has demonstrated that, while there are some fixed costs that come with urinary studies, the majority of the associated financial output is accounted for by administrative aspects (e.g. human resources $)^{(34,54)}$. Regarding the minimum sample size, the Pan American Health Organization/WHO recommends, based on available evidence, that countries plan for samples of at least 150-200 participants for each population stratum of interest (i.e. disaggregated by sex, region, socio-economic status, etc.) to achieve valid results for tracking impacts ${ }^{(6,55)}$.

Other barriers countries may face in implementing national salt reduction strategies include a lack of available data on salt content of manufactured foods. Moreover, many countries may not have the capacity to perform a comprehensive food analysis to assess the salt levels of the main food categories. In many developing countries, the informal sector plays an important role within the food industry. The salt content of food sold in this sector, such as by individual street vendors, is variable, as the relevant actors may not be prepared to set recipes and standards ${ }^{(34)}$.

By the same token, salt reduction strategies may not always make it on to the list of key priorities within a government agenda. Countries may be faced with a plethora of competing priorities, and thus may not be able to allocate sufficient resources to salt reduction activities within their national strategies. Germany, for example, has to date not pursued a national salt initiative, citing a 'lack of convincing evidence' for putting salt on the agenda; based on national nutrition surveys, salt intake in Germany is regarded as relatively low and thus not a priority for intervention ${ }^{(15)}$.

Similarly, advocacy groups in the form of consumer organizations are not always present in low-resource settings and, even where present, may not have sufficient influence to drive the political agenda. Public awareness campaigns, meanwhile, can be expensive, especially when it comes to traditional forms of media such as television airtime and printed media - and, moreover, may not even be effective, especially for low-income groups, in the absence of supportive structural mechanisms for action (e.g. availability of affordable low-salt bread in Turkey). Even when resources are available, countries may not have sufficient experience in running public awareness initiatives.

Beyond these key internal dynamics, the importance of a solid structure for governance capable of responding in a proactive, timely and effective manner to activities such as trade flows - which have the potential to undermine a national salt reduction initiative and widen inequalities must also be considered. The current analysis has identified that food trade flows and their potential health equity impacts have not been addressed as part of any salt reduction policy at the European level. A key example is bread importation-exportation. Countries with a fully implemented salt reduction policy have on certain occasions imported large quantities of foods high in salt from other Member States with no or limited salt reduction policies set in place.

Finally, although cost-effectiveness modelling has highlighted potential societal and medical savings through reduced hypertension and related $\mathrm{CVD}^{(47)}$, estimating reformulation costs remains problematic ${ }^{(56)}$. While reformulation is a common event, it is usually done to reduce the cost of producing foods, and the savings derived from production cost reductions typically cover the costs of research and development ${ }^{(57)}$. As salt is a relatively inexpensive ingredient, there may be few profits derived from reformulation in this arena. Moreover, to aid manufacturers in maintaining safety, government agencies, trade associations and research institutions may need to work with food processors to avoid reformulations that might heighten the risk for food-borne disease ${ }^{(53)}$.

It is important to acknowledge that the proposed salt reduction strategies will entail substantial investment by both industry and government. In this context, there is a 


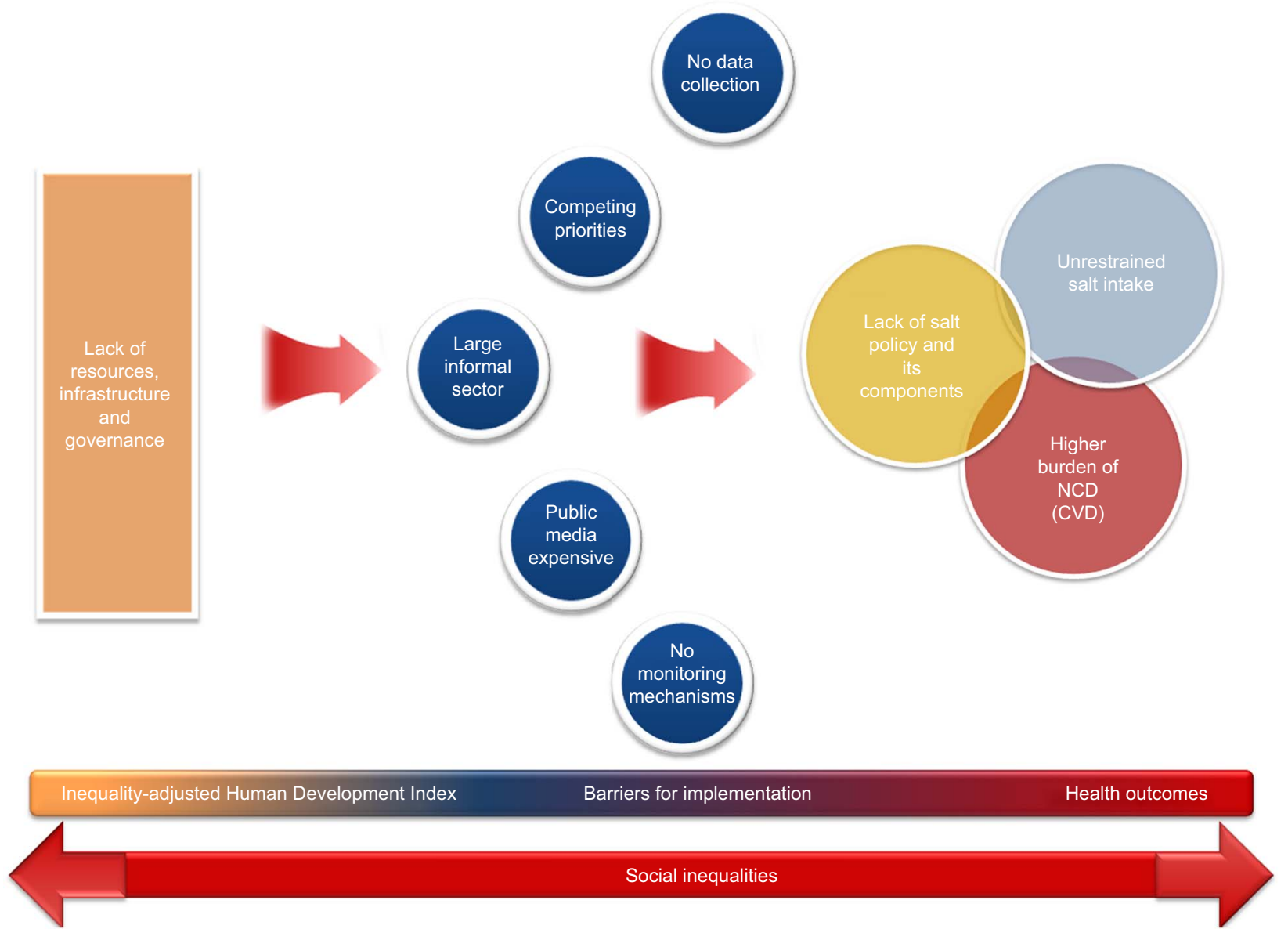

Fig. 2 (colour online) Flow diagram depicting a model for the interaction of factors driving the link between national salt initiatives and inequality-adjusted human development. An interruption of the cycle can only be achieved by means of effective interventions targeting the general population towards narrowing the gaps (NCD, non-communicable diseases)

clear need, especially in developing countries, for accurate information on the full costs and cost-effectiveness of initiatives to reduce sodium intake, along with a clear understanding of what is involved in implementing and scaling up these population-level strategies. Despite lingering uncertainties over the costs, given the stated magnitude of the benefits, the social benefit-cost ratio is ultimately likely to remain favourable to reformulation in the context of salt reduction initiatives ${ }^{(56)}$.

\section{The politics of salt: controversies and resistance}

Although few would dispute the benefits to population health of reducing salt intake, other considerations have complicated the issue and created space for politically charged debate $e^{(11,58)}$. Recognizing and tackling such issues through thoughtful coordination and regulatory measures is critical to effective programme implementation at the national level.

In the public health community, concerns have been raised that initiatives to reduce dietary salt could adversely impact programmes to prevent iodine deficiency disorders, as prevention strategies for iodine deficiency disorders rely primarily on the fortification of salt ${ }^{(59)}$. Ultimately, salt intake can certainly be reduced without compromising micronutrient fortification ${ }^{(13)}$, but monitoring of urinary iodine is essential to adjust the levels of fortification within the goal of reducing salt consumption. At the country level, creating linkages between salt iodization and salt reduction programmes presents an opportunity that is compatible, cost-effective and of great public benefit ${ }^{(11,60-62)}$ - as evidenced by successful national salt strategies utilizing iodized salt in processed foods in the Netherlands, Belgium and Italy, for example ${ }^{(63,64)}$.

For various reasons, the food industry is frequently resistant to movement towards population-wide reductions in salt intake - on top of the costs of reformulation and labelling, high salt content generally makes food more palatable and hence more marketable. Governments, meanwhile, may lack the political will to take action, faced with competing chronic disease priorities, limited resources and capacity, and pressure from the food industry lobbies. Yet success stories can be found. In the UK, for example, media campaigns and voluntary agreements with the food industry have already achieved a $1 \mathrm{~g}$ reduction in salt 
consumption, and even greater reductions might be entirely feasible through more muscular regulatory approaches. To wit, the $6 \mathrm{~g}$ reductions in Finland and Japan were achieved in spite of discordant cultural traditions and resistance from the industry ${ }^{(65,66)}$.

\section{Moving forward: minding the gaps}

Population-based salt reduction initiatives are a critical part of the public health effort to tackle NCD both in terms of mortality and morbidity. To enable improved population coverage and impact, it is important that national salt reduction initiatives are designed, implemented and monitored with regard to their differential impact on different socio-economic groups in the population. While there is debate about the most effective entry point for population gain, global evidence indicates that it is about ensuring that the environmental and structural mechanisms are in place to enable people to make and sustain positive health behaviours ${ }^{(67)}$ such as salt reduction at the individual level: making healthy choices the easier choices ${ }^{(68)}$.

An equity focus in the design, implementation and monitoring of national salt reduction initiatives is therefore about identifying whether some groups in the population are more likely to be differentially exposed to higher salt intake due to their socio-economic circumstances. Where this is the case, the emphasis should be on tailoring actions within the national initiative to ensure that such groups can benefit equally from the national initiative - for example, through regulation to ensure that low-salt bread and other products do not cost more than the standard food products, as well as through raising public awareness ${ }^{(11,58)}$. As identified, an equity focus should also involve assessing the potential health impacts of trade flows (such as importation of bread) and the potential distribution of these health impacts (e.g. the imported bread with higher salt levels may cost less and therefore be purchased by those with less disposable income for food). This is important to ensuring overall policy coherence within national salt reduction initiatives.

What remains clear is that overarching strategies based on solid evidence, such as reformulations to halve the salt content of bread, should be introduced in combination with other interventions known to be effective. There are important and reasonably quick health impacts to be had. Moreover, these initiatives should target not only those groups identified as high-risk but rather the population as a whole to achieve a narrowing of social inequalities through a broad and equitable distribution of the benefits of low-salt foods ${ }^{(69)}$. To ensure effective impact from population initiatives, however, it is important that monitoring strategies for salt reduction initiatives explicitly consider differential impacts. This can be done through the collection and analysis of data disaggregated by age, sex and several socio-economic measures (e.g. education, income and/or place of residence). By paying due attention to social and regional disparities, effective salt reduction policies have the potential to bridge the gaps rather widen them.

\section{Acknowledgements}

Sources of funding: This research received no specific grant from any funding agency in the public, commercial or not-for-profit sectors. Conflicts of interest: The authors declare that they do not have any conflicts of interest in relation to this article. Authors' contributions: J.B. and F.P.C contributed equally. R.R.-F., M.S. and J.B. conceived and designed the review; R.R.-F., M.S. and R.M.A. analysed the compiled data and wrote the paper; S.J.S., J.B. and F.P.C. reviewed the article and provided critical input. All authors read and approved the final manuscript.

\section{References}

1. Alwan A, Maclean DR, Riley LM et al. (2010) Monitoring and surveillance of chronic non-communicable diseases: progress and capacity in high-burden countries. Lancet 376, 1861-1868.

2. World Health Organization (2011) Global Status Report on Noncommunicable Diseases 2010. Geneva: WHO; available at http://www.who.int/nmh/publications/ncd_ report2010/en/

3. World Health Organization (2009) Mortality and Burden of Diseases Estimates for WHO Member States in 2004. Geneva: WHO.

4. World Health Organization (2009) Global Health Risks: Mortality and Burden of Disease Attributable to Selected Major Risks. Geneva: WHO; available at http://www.who.int/ healthinfo/global_burden_disease/GlobalHealthRisks_report_ full.pdf

5. He FJ \& MacGregor GA (2003) How far should salt intake be reduced? Hypertension 42, 1093-1099.

6. INTERSALT Cooperative Research Group (1988) INTERSALT: an international study of electrolyte excretion and blood pressure. Results for 24 hour urinary sodium and potassium excretion. BMJ 297, 319-328.

7. Dyer AR, Elliott P \& Shipley M (1994) Urinary electrolyte excretion in 24 hours and blood pressure in the INTERSALT Study. II. Estimates of electrolyte-blood pressure associations corrected for regression dilution bias. The INTERSALT Cooperative Research Group. Am J Epidemiol 139, 940-951.

8. Appel LJ \& Anderson CA (2010) Compelling evidence for public health action to reduce salt intake. $N$ Engl J Med 362, 650-652.

9. Aburto NJ, Hanson S, Gutierrez H et al. (2013) Effect of lower sodium intake on health outcomes: systematic review and meta-analysis. BMJ 346, f1326.

10. Beaglehole R, Bonita R, Horton R et al. (2011) Priority actions for the non-communicable disease crisis. Lancet 377, 1438-1447.

11. Cappuccio FP, Capewell S, Lincoln P et al. (2011) Policy options to reduce population salt intake. BMJ 343, d4995.

12. Bibbins-Domingo K, Chertow GM, Coxson PG et al. (2010) Projected effect of dietary salt reductions on future cardiovascular disease. N Engl J Med 362, 590-599.

13. Asaria P, Chisholm D, Mathers C et al. (2007) Chronic disease prevention: health effects and financial costs of strategies to reduce salt intake and control tobacco use. Lancet 370, 2044-2053. 
14. World Health Organization (2003) Diet, Nutrition and the Prevention of Chronic Diseases. Report of a Joint WHO/FAO Expert Consultation. WHO Technical Report Series no. 916. Geneva: WHO; available at http://whqlibdoc.who.int/trs/ who_trs_916.pdf

15. World Health Organization (2007) Reducing Salt Intake in Populations. Report of a WHO Forum and Technical Meeting, 5-7 October 2006, Paris, France. Geneva: WHO; available at http://www.who.int/dietphysicalactivity/Salt_ Report_VC_april07.pdf

16. Penney S (2009) Dropping the Salt: Practical Steps Countries are Taking to Prevent Chronic Non-Communicable Diseases Through Population-Wide Dietary Salt Reduction. Ottawa: Public Health Agency of Canada; available at http:// www.paho.org/english/ad/dpc/nc/salt-mtg-phac-paper.pdf

17. European Commission (2009) National Salt Initiatives: Implementing the EU Framework for Salt Reduction Initiatives. Brussels: EC; available at http://ec.europa. eu/health/ph_determinants/life_style/nutrition/documents/ national_salt_en.pdf

18. Shaw M, Dorling D \& Davey Smith G (1999) Poverty, social exclusion, and minorities. In Social Determinants of Health, pp. 211-239 [M Marmot \& RG Wilkinson, editors]. New York: Oxford University Press; available at http:// www.dannydorling.org/wp-content/files/dannydorling publication_id2407.pdf

19. James WPT (1996) Nutritional disorders affecting the heart. In Diseases of the Heart, 2nd ed., pp. 1442-1458 [DG Julian, AJ Camm, KM Fox et al., editors]. London: Elsevier Health Sciences.

20. Roos G \& Prättälä R (1999) Disparities in Food Habits: Review of Research in 15 European Countries. Publications of the National Public Health Institute B24/1999. Helsinki: Kansanterveyslaitos.

21. Nelson M, Erens B, Bates B et al. (2007) Low Income Diet and Nutrition Survey: Summary of Key Findings. A Survey Carried Out on Behalf of the Food Standards Agency (FSA). Norwich: The Stationery Office; available at http:// www.food.gov.uk/multimedia/pdfs/lidnssummary.pdf

22. Ji C, Kandala N-B \& Cappuccio FP (2013) Spatial variation of salt intake in Britain and association with socioeconomic status. BMJ Open 3, e002246.

23. van Bommel E \& Cleophas T (2012) Potassium treatment for hypertension in patients with high salt intake: a metaanalysis. Int J Clin Pharmacol Ther 50, 478-482.

24. D'Elia L, Barba G, Cappuccio FP et al. (2011) Potassium intake, stroke, and cardiovascular disease: a meta-analysis of prospective studies. J Am Coll Cardiol 57, 1210-1219.

25. Aburto NJ, Hanson S, Gutierrez H et al. (2013) Effect of increased potassium intake on health: systematic review and meta-analysis. BMJ 346, f1378.

26. Steptoe A, Perkins-Porras L, McKay C et al. (2003) Behavioural counselling to increase consumption of fruit and vegetables in low income adults: randomised trial. BMJ 326, 855-858.

27. Cappuccio FP, Rink E, Perkins-Porras L et al. (2003) Estimation of fruit and vegetable intake using a two-item dietary questionnaire: a potential tool for primary health care workers. Nutr Metab Cardiovasc Dis 13, 12-19.

28. London B, Albert C, Anderson ME et al. (2007) Omega-3 fatty acids and cardiac arrhythmias: prior studies and recommendations for future research: a report from the National Heart, Lung, and Blood Institute and Office of Dietary Supplements Omega-3 Fatty Acids and their Role in Cardiac Arrhythmogenesis Workshop. Circulation 116, e320-e335.

29. Howe LD, Tilling K, Galobardes B et al. (2011) Socioeconomic disparities in trajectories of adiposity across childhood. Int J Pediatr Obes 6, e144-e153.

30. Wardle J \& Boniface D (2008) Changes in the distributions of body mass index and waist circumference in English adults, 1993/1994 to 2002/2003. Int J Obes (Lond) 32, 527-532.
31. Clark AM, Duncan AS, Trevoy JE et al. (2011) Healthy diet in Canadians of low socioeconomic status with coronary heart disease: not just a matter of knowledge and choice. Heart Lung 40, 156-163.

32. Ni Mhurchu C, Eyles H, Dixon R et al. (2012) Economic incentives to promote healthier food purchases: exploring acceptability and key factors for success. Health Promot Int 27, 331-341.

33. Whiting D, Unwin N, Roglic G et al. (2010) Diabetes: equity and social determinants. In Equity, Social Determinants and Public Health Programmes, pp. 77-94 [E Blas, editor]. Geneva: WHO.

34. Organisation for Economic Co-operation and Development (1999) Purchasing Power Parities and Real Expenditure. Results 1996. Paris: OECD.

35. Commission on Social Determinants of Health (2008) Closing the Gap in a Generation: Health Equity Through Action on the Social Determinants of Health. Geneva: WHO; available at http://whqlibdoc.who.int/publications/ 2008/9789241563703_eng.pdf

36. World Health Organization (2011) Strategies to Monitor and Evaluate Population Sodium Consumption and Sources of Sodium in the Diet. Report of a Joint Technical Meeting Convened by WHO and the Government of Canada, Calgary, 19-20 October 2010. Geneva: WHO; available at http://whqlibdoc.who.int/publications/2011/ 9789241501699_eng.pdf

37. Stuckler D (2008) Population causes and consequences of leading chronic diseases: a comparative analysis of prevailing explanations. Milbank $Q$ 86, 273-326.

38. World Health Organization (2010) The World Health Report. Health Systems Financing: The Path to Universal Coverage. Geneva: WHO; available at http://whqlibdoc. who.int/whr/2010/9789241564021_eng.pdf

39. World Bank (2011) The Growing Danger of Noncommunicable Diseases - Acting Now to Reverse Course. Washington, DC: World Bank; available at http://site resources.worldbank.org/HEALTHNUTRITIONANDPOPU LATION/Resources/Peer-Reviewed-Publications/WBDee peningCrisis.pdf

40. World Health Organization (2008) 2008-2013 Action Plan for the Global Strategy for the Prevention and Control of Noncommunicable Diseases. Geneva: WHO; available at http:// whqlibdoc.who.int/publications/2009/9789241597418_eng.pdf

41. Suhrcke M, Nugent RA, Stuckler D et al. (2006) Chronic Disease: An Economic Perspective. London: The Oxford Health Alliance; available at http://www.sehn.org/tccpdf/ Chronic\%20disease\%20economic\%20perspective.pdf

42. Abegunde DO, Mathers CD, Adam T et al. (2007) The burden and costs of chronic diseases in low-income and middle-income countries. Lancet 370, 1929-1938.

43. Lorenc T, Petticrew M, Welch V et al. (2012) What types of interventions generate inequalities? Evidence from systematic reviews. J Epidemiol Community Health 67, 190-193.

44. Benach J, Malmusi D, Yasui Y et al. (2012) A new typology of policies to tackle health inequalities and scenarios of impact based on Rose's population approach. J Epidemiol Community Health 67, 286-291.

45. Shankar B, Brambila-Macias J, Traill B et al. (2013) An evaluation of the UK Food Standards Agency's salt campaign. Health Econ 22, 243-250.

46. Sutherland J, Edwards P, Shankar B et al. (2013) Fewer adults add salt at the table after initiation of a national salt campaign in the UK: a repeated cross-sectional analysis. Br J Nutr (Epublication ahead of print version).

47. United Nations Development Programme (2011) Human Development Report 2011. Sustainability and Equity: A Better Future for All. New York: UNDP; available at http:// www.undp.org/content/undp/en/home/librarypage/hdr/ human_developmentreport2011.html 
48. Webster JL, Dunford EK, Hawkes C et al. (2011) Salt reduction initiatives around the world. J Hypertens 29, 1043-1050.

49. Kroke A, Boeing H, Rossnagel K et al. (2004) History of the concept of 'levels of evidence' and their current status in relation to primary prevention through lifestyle interventions. Public Health Nutr 7, 1134-1144.

50. Alderman MH (2010) Reducing dietary sodium: the case for caution. JAMA 303, 448-449.

51. McCarron DA, Geerling JC, Kazaks et al. (2009) Can dietary sodium intake be modified by public policy? Clin J Am Soc Nephrol 4, 1878-1882.

52. Beauchamp GK, Bertino M \& Engelman K (1987) Failure to compensate decreased dietary sodium with increased table salt usage. JAMA 258, 3275-3278.

53. Institute of Medicine (2010) Strategies to Reduce Sodium Intake in the United States. Washington, DC: National Academies Press.

54. Ji C, Sykes L, Paul C et al. on behalf of the Sub-Group for Research and Surveillance of the PAHO/WHO Regional Expert Group for Cardiovascular Disease Prevention Through Population-wide Dietary Salt Reduction (2012) Systematic review of studies comparing 24-hour and spot urine collections for estimating population salt intake. Rev Panam Salud Publica 32, 307-315.

55. World Health Organization/Pan American Health Organization (2010) Protocol for Population-Level Sodium Determination in 24-hour Urine Samples. Washington, DC: WHO/PAHO.

56. Webster J (2009) Reformulating Food Products for Health: Context and Key Issues for Moving Forward in Europe. Sydney: The George Institute for International Health.

57. Kramer F (2002) Initial and progressive cost estimates. In Food Product Development: Based on Experience, pp. 179-188 [C Side, editor]. Ames, IA: Iowa State Press.

58. Cappuccio FP (2007) Salt and cardiovascular disease. BMJ 334, 859-860.

59. Verkaik-Kloosterman J, van 't Veer P \& Ocké MC (2010) Reduction of salt: will iodine intake remain adequate in the Netherlands? Br J Nutr 104, 1712-1718.

60. World Health Organization (2007) Salt as a Vebicle for Fortification. Report of a WHO Expert Consultation, Luxembourg, 21-22 March 2007. Geneva: WHO; available at http://whqlibdoc.who.int/publications/2008/ 9789241596787_eng.pdf

61. World Health Organization/Pan American Health Organization Regional Expert Group for Cardiovascular Disease Prevention through Population-wide Dietary Salt Reduction (2011) Improving Public Health in the Americas by Optimizing Sodium and Iodine Intakes. Report from the Washington, DC Meeting, April 2011. Washington, DC: WHO/PAHO.

62. Campbell N, Dary O, Cappuccio FP et al. (2012) A call for action to coordinate programs to improve global health by optimizing salt and iodine intake. Bull World Health Organ 90, 73-74.

63. Vandevijvere S (2012) Sodium reduction and the correction of iodine intake in Belgium: policy options. Arch Public Health 70, 10.

64. Ohlhorst SD, Slavin M, Bhide JM et al. (2012) Use of iodized salt in processed foods in select countries around the world and the role of food processors. Compr Rev Food Sci Food Saf 11, 233-284.

65. He FJ \& MacGregor GA (2009) A comprehensive review on salt and health and current experience of worldwide salt reduction programmes. J Hum Hypertens 23, 363-384.

66. Laatikainen T, Critchley J, Vartiainen $\mathrm{E}$ et al. (2005) Explaining the decline in CHD mortality in Finland between 1982 and 1997. Am J Epidemiol 162, 764-773.

67. Blas E \& Sivasankara Kurup A (2010) Introduction and methods of work. In Equity, Social Determinants and Public Health Programmes, pp. 38-47 [E Blas and A Sivasankara Kurup, editors]. Geneva: WHO.

68. World Health Organization Regional Office for Europe (2011) Action Plan for Implementation of the European Strategy for the Prevention and Control of Noncommunicable Diseases 2012-2016. Regional Committee for Europe, Sixty-first Session, Baku, Azerbaijan, 12-15 September 2011 (EUR/ RC61/12). Copenhagen: WHO Regional Office for Europe; available at http://www.euro.who.int/_data/assets/pdf_file/ 0003/147729/wd12E_NCDs_111360_revision.pdf

69. Scholes S, Bajekal M, Love $\mathrm{H}$ et al. (2012) Persistent socioeconomic inequalities in cardiovascular risk factors in England over 1994-2008: a time-trend analysis of repeated cross-sectional data. BMC Public Health 12, 129. 